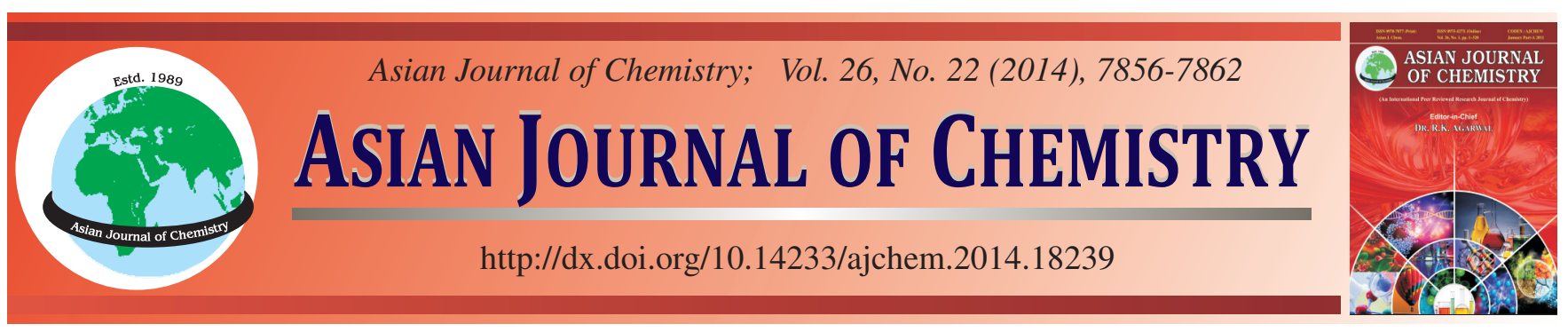

\title{
Why Does Inulin have Pharmacological Activity? Theoretical Research by DFT and Concept DFT Methods
}

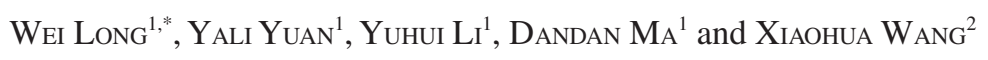

${ }^{1}$ School of Chemistry and Chemical Engineering, University of South China, Hengyang 421001, Hunan Province, P.R. China

${ }^{2}$ School of Chemistry and Chemical Engineering, Xiang Tan University, Xiangtan 411105, Hunan Province, P.R. China

*Corresponding author: Tel/Fax: +86 734 8281675; E-mail: 1rj2010@foxmail.com

\begin{abstract}
The geometric structure optimization, frequency analysis, infrared spectroscopy, natural charge population, the natural bond orbital (NBO) analysis, the molecular and the frontier orbital energy are calculated about glucose, pyran-fructose, furfuran-fructose and inulin molecule by using density functional theory (DFT) method in B3LYP on the 6-311+g(d,p) basis set level. It is shown the stability order is: furfuran-fructose $>$ pyran-fructose $>$ glucose $>$ inulin. We find that inulin's chemical potential is maximum, the chemical hardness is minimum and the electrophilicity index is maximum using the concept DFT method, which could account for it's pharmacological activity. The Fukui function scanning has shown the $\mathrm{C}_{2}$ atom in inulin molecule has strong electron-losing ability and it is the active center in the molecule. The $\mathrm{E}_{\mathrm{BDE}}$ calculation has shown the position of $\mathrm{O}^{2-}-\mathrm{H}$ is the most easily broken off and the bond energy is only $94.65 \mathrm{kcal}$ $\mathrm{mol}^{-1}$, which is far less than the adiabatic ionization potential value, all of that could be a reasonable theoretical interpretation for the pharmacological activity of inulin.
\end{abstract}

Keywords: Inulin, Pharmacological activity, Density functional theory, FuKui function.

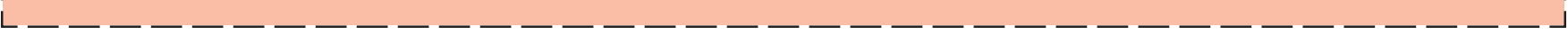

\section{INTRODUCTION}

There is currently considerable interest given to inulin due to their pharmacological activities ${ }^{1-6}$. Jerusalme artichoke which has abound of inulin is large-area plant in China and many kinds of fungi also has inulin. We foundd the plant which involved inulin, it will be a wild reproductive capacity and high adaptability, so the inulin has the unique advantages of high resistance to the pest invasion. It is easy to reach high foison except manual weeding and fertilization all of that have been led to scientists' attention. Jerusalem artichoke tubers like fruit not only contain glucose, but also have a large number of inulin, which could better resist to pest invasion by the magic ingredient and many experiments ${ }^{7-12}$ have done about inulin for its magic affection. But the theoretical research about inulin have not been reported.

Clinical pharmacology property of inulin, which is nontoxic, heat and cooling blood detoxification, diuresis, detumescence and it is good antibacterial and antiphlogistic effect and widely used in disease cure as fever, diarrhea and many other diseases ${ }^{13}$. It is magical two-way regulating blood pressure function. When hypertensive patients used by inulin, which can reduce the blood sugar concentration and when hypotension patients used by inulin, which can raise blood glucose concentration ${ }^{14}$. Stevioside (CAS number: 57817-89-7) is a macromolecular system, It is shown in Fig. 1 (a), and the formula is $\mathrm{C}_{38} \mathrm{H}_{60} \mathrm{O}_{18}$, inulin molecule is obtained after stevioside hydrolysis. $\mathrm{Chi}^{13}$ has found that it is good oxidation resistance of inulin through experiments, inulin is selective catalytic function better to radical $\left({ }^{\circ} \mathrm{OH}\right)$ and superoxide anion free radical $\left(\mathrm{O}_{2}^{-\bullet}\right)$ in the human body, but the real process is not clearly.

Predicting drug activity by the theory of chemical simulation calculation has been widely reported ${ }^{15,16}$, we have chose D-marigold sugar (CAS number: 87-81-0) as the investigate object (formula $\mathrm{C}_{6} \mathrm{H}_{12} \mathrm{O}_{6}$ ), contrasted to glucose, pyranfructose, fructose and furfuran-fructose. We have compared to the differences in their pharmacological activity by the concept DFT activity index ${ }^{17,18}$ and scanned charge in inulin by FuKui function ${ }^{19}$, in order to predicting the active position and different ability.

\section{EXPERIMENTAL}

The geometry optimization of each species selected is carried out using DFT/B3LYP methods with 6-311+g(d,p) basis $\operatorname{sets}^{20}$. The vibrational frequencies are calculated at B3LYP/6-311+g(d,p) level of theory for the optimized structure and the obtained frequencies are scaled by $0.9613^{21}$. In 


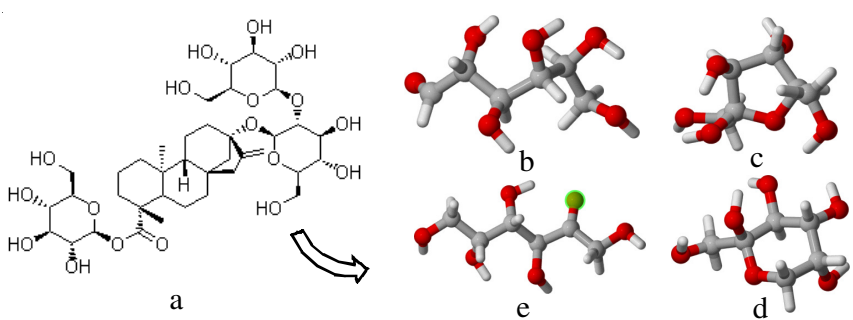

Fig. 1. Structure of five molecules

addition, the other computations have also been done by the same method with the same basis set. We have found the all vibration frequency of each stable molecule are positive through vibration frequency analysis, which could certify all calculate details are effective and credible.

In order to study the different structure about inulin, taking into account for the different solubility of them, we have chose PCM model solvent construction by water. At the same time, we have done the molecular orbital analysis and charge distribution on different system and we have obtained the charge value using the natural bond orbital (NBO) analysis ${ }^{22}$. Density functional activity index is very effective in predicting the pharmacological reactivity and local selective ${ }^{23}$. In DFRT framework, the global react index such as chemical potential $\mu$ and chemical hardness $\eta$ are defined as:

$$
\begin{gathered}
\mu=-\chi=(\partial \mathrm{E} / \partial \mathrm{N})_{v} \\
\eta=\left(\partial^{2} \mathrm{E} / \partial \mathrm{N}^{2}\right)_{v}=(\partial \mu / \partial \mathrm{N})_{v}
\end{gathered}
$$

Meanwhile, $\mathrm{E}$ is the total energy of the system, $\mathrm{N}$ is the total number of electron in system, $v$ is the external potential energy, $\mu$ can be defined as the negative value of electro negativity $\chi$. According to the principle of Mulliken ${ }^{24}, \mu=-\chi=-$ (I $+\mathrm{A}) / 2$. But Pearson ${ }^{25}$ have suggested that $\eta=\mathrm{I}-\mathrm{A}$, I is the first ionization potentials and $\mathrm{A}$ is the electron affinities. According to the closed shell theory, $\mathrm{I} \approx-\mathrm{E}_{\text {Hомо }}$ and $\mathrm{A} \approx-\mathrm{E}_{\mathrm{LUMO}}$, while $\mathrm{E}_{\text {номо }}$ is the highest occupied molecular orbital energy and $\mathrm{E}_{\mathrm{LUMO}}$ is the lowest occupied molecular orbital energy. Parr and $\mathrm{Liu}^{26}$ have proposed the electric affinity index as $\omega=\mu^{2} / 2 \eta$ and the force affinity index as $\Delta \mathrm{E}_{\mathrm{n}}=-\mathrm{A}+\omega=(\mu+\eta)^{2} / 2 \eta$, the electric affinity index as $\Delta \mathrm{E}_{\mathrm{e}}=\mathrm{I}+\omega=(\mu-\eta)^{2} / 2 \eta$.

Localized reactivity index can be described by the Fukui function $^{26}$. Which are the first order derivative between electron density $(\mathrm{R})$ and the electron number $(\mathrm{N})$. Because the Fukui function is discontinuous, we have simplified the affinity electric Fukui function as $f_{(r)}^{-}$, the affinity nuclear Fukui function as $f_{(\mathrm{r})}^{+}$and the free radical Fukui function as $f_{(\mathrm{r})}^{0}$.

$$
\begin{aligned}
& f_{(\mathrm{r})}=\left(\partial \rho_{(\mathrm{r})} / \partial_{\mathrm{N}}\right)_{v} \\
& f^{-}(\mathrm{r})=\rho_{\mathrm{N}(\mathrm{r})}-\rho_{\mathrm{N}-1(\mathrm{r})} \\
& f^{+}{ }_{(\mathrm{r})}=\rho_{\mathrm{N}+1(\mathrm{r})}-\rho_{\mathrm{N}(\mathrm{r})} \\
& f^{0}{ }_{(\mathrm{r})}=\left(f^{+}{ }_{(\mathrm{r})}+f^{-}{ }_{(\mathrm{r})}\right) / 2
\end{aligned}
$$

While $\rho_{\mathrm{N}(\mathrm{r})}$ is the electron density of neutral molecules and $\rho_{\mathrm{N}-1(\mathrm{r})}$ is cationic electron density and $\rho_{\mathrm{N}+1(\mathrm{r})}$ is anionic electron density. We have studied hydroxylic chemical activity in order to certify the better oxidation resistance of inulin. There are two kinds of molecular reaction mechanisms ${ }^{27,28}$ about free radical scavenging an tioxid ants: (1) In nonpolar solvent, the straight pull hydrogen abstraction reaction could achieve the purpose, so the theoretical parameter is $\mathrm{O}-\mathrm{H}$ bond dissociation energy (bond dissociation enthalpy, referred as $\mathrm{BDE}$ ), when $\mathrm{E}_{\mathrm{BDE}}$ is more lesser, the reaction could carry on more easily; (2) In polar solvent, a proton electron transfer reaction could carry out is the chief character and the theoretical parameters is ionization potential (IP). When IP is lesser, the reaction could carry on more easily. As the human body is more complex, oxidation resistance performance of hydroxyl often need measured combine $\mathrm{E}_{\mathrm{BDE}}$ and IP parameter.

$\mathrm{E}_{\mathrm{BDE}}=\mathrm{H}_{\mathrm{f}}+\mathrm{H}_{\mathrm{h}}-\mathrm{H}_{\mathrm{p}}=\left(\mathrm{SPE}_{\mathrm{f}}+\mathrm{ZPVE}_{\mathrm{f}} \times \mathrm{v}+3 / 2 \mathrm{RT}+3 / 2 \mathrm{RT}\right.$ $+\mathrm{RT})+\mathrm{H}_{\mathrm{h}}-\left(\mathrm{SPE}_{\mathrm{p}}+\mathrm{ZPVE}_{\mathrm{p}} \times \mathrm{v}+3 / 2 \mathrm{RT}+3 / 2 \mathrm{RT}+\mathrm{RT}\right)=$ $\left(\mathrm{SPE}_{\mathrm{f}}+\mathrm{ZPVE}_{\mathrm{f}} \times \mathrm{v}\right)+\mathrm{H}_{\mathrm{h}}\left(\mathrm{SPE}_{\mathrm{p}}+\mathrm{ZPVE}_{\mathrm{p}} \times \mathrm{v}\right)$

$$
\mathrm{IP}=\mathrm{H}_{\mathrm{c}}-\mathrm{H}_{\mathrm{p}}
$$

The SPE is the electron energy, ZPVE is the zero point energy and $v$ is correction factor as $0.9804, \mathrm{H}_{\mathrm{p}}$ is the enthalpy of parent molecule and $\mathrm{H}_{\mathrm{h}}$ is enthalpy of one hydrogen atom (0.49764 a.u.), also $\mathrm{H}_{\mathrm{f}}$ is enthalpy of the free radical which parent molecule have lost one hydrogen atom, $\mathrm{H}_{\mathrm{c}}$ is the formation enthalpy of the radical cation in response. All calculations are finished by Gaussian 03 program ${ }^{29}$, taking into account of the really existence state of molecules, we have constructed the solvent model (PCM) and the solvent is water, part of the images have been analyzed and plotted through utilized Gaussian-view, NBO, Multiwfn 2.5 program $^{30}$.

\section{RESULTS AND DISCUSSION}

Geometry optimization: As shown in Fig. 1, a is stevioside molecule, e is D-Marigold-inulin molecule after hydrolysis from a, b is glucose molecule, $\mathrm{c}$ is pyran-fructose molecule and $d$ is furfuran-fructose molecule (the following as same). In the opinion of the molecular structure, they all have hydroxyl group, molecular formula is $\mathrm{C}_{6} \mathrm{H}_{12} \mathrm{O}_{6}$ except a and all of that could be dissolved in water in order to be absorbed into the cell. Obvious difference is that there are a carbon atom ring in c and d molecule, only there is a carbonyl $(\mathrm{C}=\mathrm{O})$ in $\mathrm{e}$ molecule and there is a radical (-CHO) in b molecule. In order to compare the different of molecular structure, we have chose B3LYP/6-311+g(d,p) method combined with the PCM solvent model (solvent is water) to optimize the geometry molecular structure. We also have done analysis of harmonic frequency vibration after stable structure have been found, all results are positive which could indicate the molecule is stable.

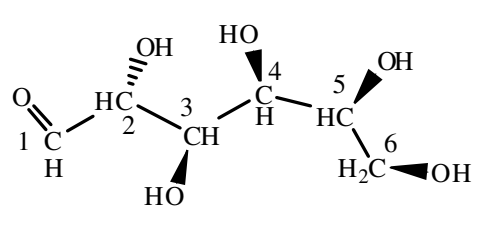

b

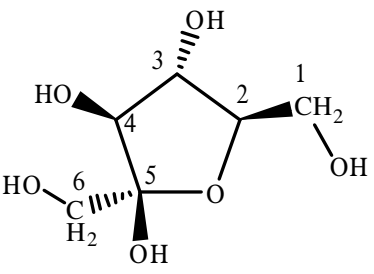

c

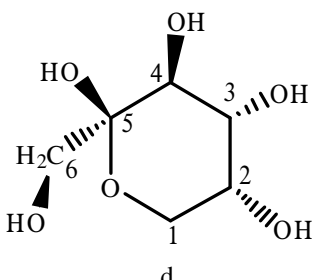

d<smiles>[1H][C@@H](CO)[C@@H](O)[C@@H](O)C([CH])=O</smiles>

e

Fig. 2. Carbon atom number in the molecule 


\begin{tabular}{|c|c|c|c|c|c|c|c|c|c|c|c|}
\hline \multicolumn{12}{|c|}{$\begin{array}{l}\text { TABLE-1 } \\
\text { SELECTED BOND LENGTH }(\mathrm{nm}) \text { AND BOND ANGLES }\left({ }^{\circ}\right)\end{array}$} \\
\hline Length & $\mathrm{C}_{1}-\mathrm{C}_{2}$ & $\mathrm{C}_{2}-\mathrm{C}_{3}$ & $\mathrm{C}_{3}-\mathrm{C}_{4}$ & $\mathrm{C}_{4}-\mathrm{C}_{5}$ & $\mathrm{C}_{5}-\mathrm{C}_{6}$ & $\mathrm{C}_{1}-\mathrm{O}$ & $\mathrm{C}_{2}-\mathrm{O}$ & $\mathrm{C}_{3}-\mathrm{O}$ & $\mathrm{C}_{4}-\mathrm{O}$ & $\mathrm{C}_{5}-\mathrm{O}$ & $\mathrm{C}_{6}-\mathrm{O}$ \\
\hline $\mathrm{c}$ & 0.1530 & 0.1530 & 0.1540 & 0.1560 & 0.1530 & 0.1420 & 0.1450 & 0.1430 & 0.1410 & 0.1420 & 0.1430 \\
\hline d & 0.1530 & 0.1530 & 0.1530 & 0.1550 & 0.1540 & 0.1430 & 0.1420 & 0.1420 & 0.1440 & 0.1430 & 0.1410 \\
\hline $\mathrm{e}$ & 0.1520 & 0.1530 & 0.1550 & 0.1540 & 0.1530 & 0.1400 & 0.1220 & 0.1430 & 0.1410 & 0.1430 & 0.1420 \\
\hline $\mathrm{b}$ & 124.9 & 110.2 & 109.1 & 104.8 & 112.8 & 109.7 & 114.4 & 108.0 & 114.7 & 106.4 & \\
\hline $\mathrm{c}$ & 110.5 & 108.4 & 115.1 & 107.4 & 103.1 & 109.8 & 103.2 & 110.1 & 114.3 & 106.8 & \\
\hline d & 112.7 & 109.3 & 109.3 & 107.7 & 110.6 & 105.4 & 111.3 & 108.7 & 112.9 & 111.6 & \\
\hline e & 109.3 & 122.2 & 117.5 & 113.1 & 109.0 & 108.7 & 111.2 & 112.7 & 113.1 & 110.2 & \\
\hline
\end{tabular}

As shown in Table-1 (the carbon atom number was shown in Fig. 2), we have found that the bond length of four isomeric molecule are almost equal, the molecules could exist stable and the $\mathrm{C}-\mathrm{C}$ bond length in furan-fructose and pyran-fructose is as same as long and straight in chain molecule, but the intra molecular angle data is $110^{\circ}$, which is not more different as the straight chain molecule's angle is $119^{\circ}$, so there is conducive to the stability of molecules. The bond length of $\mathrm{C}_{1}=\mathrm{O}$ is $0.1200 \mathrm{~nm}$ in b molecule and the bond length of $\mathrm{C}_{2}=\mathrm{O}$ is 0.1220 $\mathrm{nm}$ in e molecule, which is caused by the different of aldehyde groups. The bond angle near the $\mathrm{C}_{2}$ is not $120^{\circ}$ and deflect from $s p^{2}$ is due to the group electron attraction of oxygen atom in e molecule. In all the error between molecular structure data and experimental parameter ${ }^{31-33}$ is minimum, so their molecular structure is credible.

Infrared spectroscopy: We have done single frequency analysis of four molecule stability by the Gaussian 03 program $^{29}$ and we have found all vibration frequency is positive. The simple harmonic vibration have been attached by the Gauss-View program, we have drew the infrared spectra of four molecules as shown in Fig. 3, the results are reasonable. We have found that there are molecular vibration fingerprint
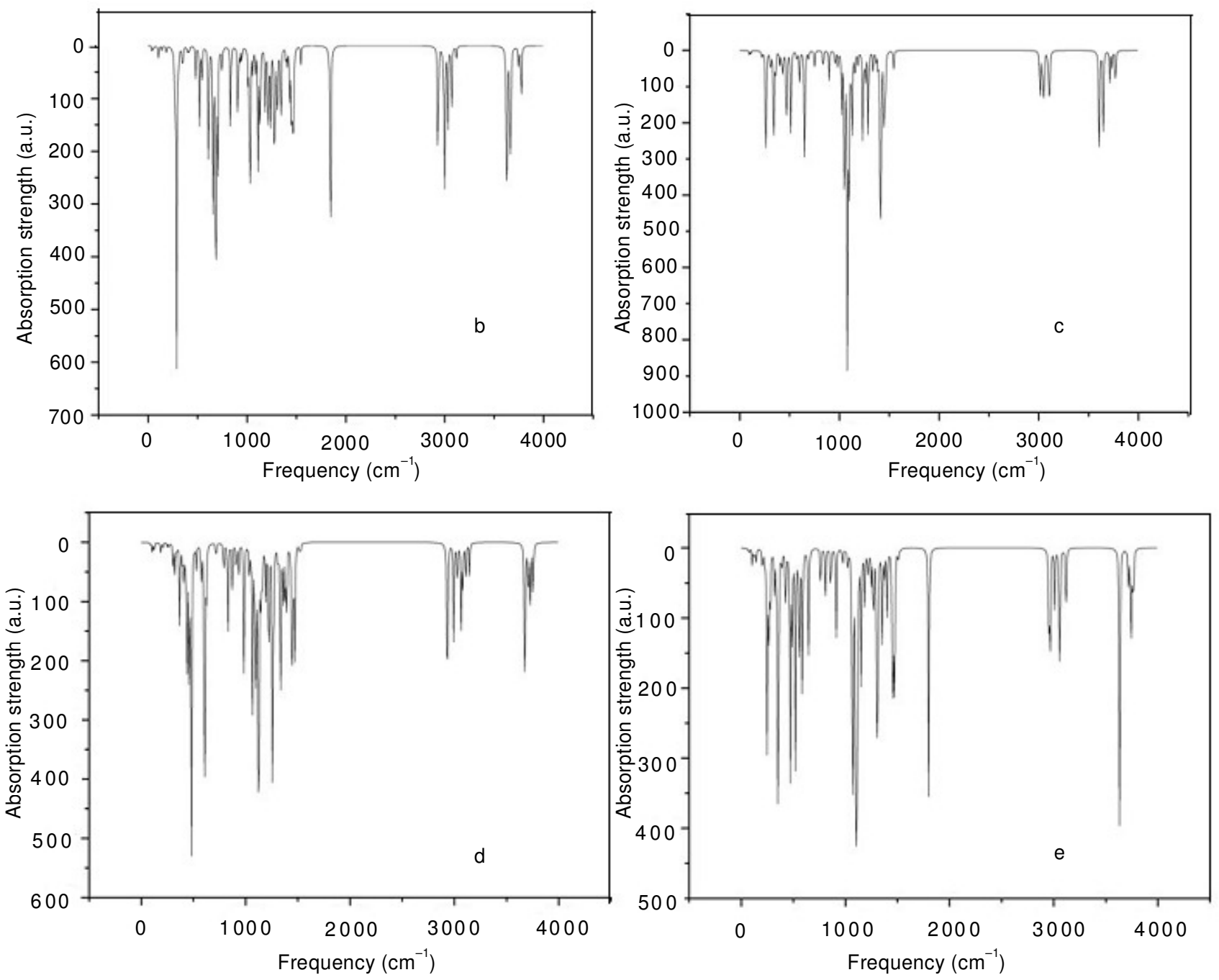

Fig. 3. Infrared spectra of four molecules 
peaks are appeared between 1300 to $400 \mathrm{~cm}^{-1}$ are due to the vibration of the total molecule. The absorption peak are appeared between 1400 to $1000 \mathrm{~cm}^{-1}$ are due to the stretching vibration of $\mathrm{C}-\mathrm{O}$ bond in the molecules (including primary alcohol, secondary alcohol and tertiary alcohol). There is one strong absorption peak is appeared at $1100 \mathrm{~cm}^{-1}$ in $\mathrm{c}$ and $\mathrm{d}$ molecules are due to the asymmetric stretching vibration of $\mathrm{C}-\mathrm{O}-\mathrm{C}$ bonds, but the molecule $\mathrm{b}$ is not same as them. There is one strong absorption peak appeared at $1700 \mathrm{~cm}^{-1}$ in e molecule is due to the vibration of the carbonyl $(\mathrm{C}=\mathrm{O})$ bond and there are some strong absorption peaks appeared at $2900 \mathrm{~cm}^{-1}$ in b molecule due to the vibration of $\mathrm{C}-\mathrm{H}$ bonds and some uncorrected results of frequency about $2820 \mathrm{~cm}^{-1}$. There are two areas of many small absorption peaks larger than $3000 \mathrm{~cm}^{-1}$, which are mainly caused by the expansion of $\mathrm{C}-\mathrm{H}$ bond and the stretching of $\mathrm{O}-\mathrm{H}$ bond.

Natural bond orbital (NBO) analysis: In order to compared atoms in the four molecules, we have done the atom charged scanning by NBO program. As the distribution of natural charge belong to atom is shown in Table-2. It is not difficult to found both the $\mathrm{C}_{1}$ atom in $\mathrm{b}$ molecule and the $\mathrm{C}_{2}$ atom in e molecule have shown strong positive charge owing to strongly attraction of electronegative oxygen atom in $\mathrm{C}=\mathrm{O}$ bond. How much atomic charge of carbon atoms is account for the connected number of oxygen atoms and hydrogen atoms. The $\mathrm{C}_{5}$ atom has shown $0.5616 \mathrm{e}$ and $0.5492 \mathrm{e}$ both in $\mathrm{c}$ and $\mathrm{d}$ molecules are due to no hydrogen atom has contributed the positive charge. The carbon atoms of primary alcohol generally have shown more negative charges because of stericeffection, such as the $\mathrm{C}_{6}$ atom in $\mathrm{b}$ molecule and the $\mathrm{C}_{1}$ atom in e molecule. The oxygen atoms have shown negative charge in all molecules and the maximum number of negative charge is the oxygen atom which is attached with $\mathrm{C}_{6}$ atom in b molecule but not the oxygen atom in $\mathrm{C}=\mathrm{O}$, which as concerned as the contribution of the electron cloud and steric hindrance. The oxygen atom in $\mathrm{C}-\mathrm{O}-\mathrm{C}$ bond of $\mathrm{c}$ molecule and d molecule have shown $-0.6114 \mathrm{e}$ and $-0.5560 \mathrm{e}$ respectively, which indicated the connect tension between ring atoms is suitable. But the charge distribution may not be explain the stable overall, we have to judge by the natural orbit and the two order perturbation stabilization energy, the related data are listed in Table-3.

If the two order perturbation stabilization energy $\left(\mathrm{E}_{(2)}\right)$ is sourced from isolate electron pair, which could indicate the other repel force of bonds is small, so the molecular stability is better. The maximum value of $\mathrm{E}_{(2)}$ are following as donor track Donor $\mathrm{NBO}_{(\mathrm{i})} \rightarrow$ Acceptor receptor $\mathrm{NBO}_{(\mathrm{j})}$. It is not difficult to find that $\mathrm{E}_{(2)}$ between the lone pair of electrons of oxygen atom to antibonding orbital is the maximum value in b, c, d molecules in order to indicate the three molecules are stabile, but the $\mathrm{E}_{(2)}$ between $\mathrm{C}_{1}-\mathrm{H}$ bond to $\mathrm{BD}^{*}$ of $\mathrm{C}_{3}-\mathrm{O}-\mathrm{H}$ is large as $10.22 \mathrm{kcal} / \mathrm{mol}$ in e molecule could not be neglected, so that the formation of intra molecular hydrogen bond on $\mathrm{C}_{1}-\mathrm{H}$ in $\mathrm{e}$ molecule may be carried out under the affect of the oxygen atom which have attached to $\mathrm{C}_{3}$, the action can make inulin molecule into an stable structure.

Molecular energy and frontier orbit: In order to assess the stability of various molecules, We have calculated the various energy data of the four molecules at $0 \mathrm{~K}$ which are listed in Table- 4 . We have found that the $\mathrm{E}_{0}$ of furan-fructose molecule is the lowest, this may be the ring which is built of six atom could accommodate of the electrons better. The molecular energy data could indicate that the furan fructose molecule is the most stably, the relatively isomerism energy of glucose molecule energy is $50.6721 \mathrm{~kJ} / \mathrm{mol}$ and the relatively isomerism energy of inulin molecule is $43.3208 \mathrm{~kJ} / \mathrm{mol}$. The reason of this phenomenon is the linear molecule could cause the molecular volume increasing, the electron motion scope expanse in order to energy increasing. In order to judge the electronic transitions and chemical energy, we have calculated the energy level of the frontier molecular orbital, which as shown in Fig. 4. HOMO is the highest molecular orbital and

TABLE-2

NATURAL CHARGE OF ATOM IN FOUR MOLECULES

\begin{tabular}{ccccccc}
\hline Molecule & $\mathrm{C}_{1}$ & $\mathrm{C}_{2}$ & $\mathrm{C}_{3}$ & $\mathrm{C}_{4}$ & $\mathrm{C}_{5}$ & $\mathrm{C}_{6}$ \\
\hline $\mathrm{b}$ & 0.3936 & -0.0168 & 0.0635 & 0.0390 & 0.0351 & -0.1281 \\
$\mathrm{c}$ & -0.1043 & 0.0635 & 0.0462 & 0.0176 & 0.5616 & -0.1252 \\
$\mathrm{~d}$ & -0.1199 & 0.0195 & 0.0474 & -0.0063 & 0.5492 & -0.1131 \\
$\mathrm{e}$ & -0.1581 & 0.4679 & -0.0238 & 0.0426 & 0.0423 & -0.0981 \\
\hline Molecule & $\mathrm{C}_{1}-\mathrm{O}$ & $\mathrm{C}_{2}-\mathrm{O}$ & $\mathrm{C}_{3}-\mathrm{O}$ & $\mathrm{C}_{4}-\mathrm{O}$ & $\mathrm{C}_{5}-\mathrm{O}$ & -0.768 \\
\hline $\mathrm{b}$ & -0.5089 & -0.7565 & -0.7546 & -0.7751 & -0.7685 & -0.7768 \\
$\mathrm{c}$ & -0.7547 & -0.6114 & -0.7589 & -0.7381 & -0.7478 & -0.7737 \\
$\mathrm{~d}$ & -0.5560 & -0.7737 & -0.7703 & -0.7491 & -0.7416 & -0.7372 \\
$\mathrm{e}$ & -0.7223 & -0.4818 & -0.7246 & -0.7440 & -0.7688 & -0.7637 \\
\hline
\end{tabular}

TABLE-3

PARTS RESULTS OF THE COMPOUND BY NBO ANALYSIS AND THE SECOND-ORDER PERTURBATION ENERGY

\begin{tabular}{cccc}
\hline Molecule & Donor $\mathrm{NBO}_{(\mathrm{i})}$ & Acceptor $\mathrm{NBO}_{(\mathrm{i})}$ & Stabilization energies $\mathrm{E}_{(2)}(\mathrm{kcal} / \mathrm{mol})$ \\
\hline \multirow{2}{*}{$\mathrm{b}$} & $\mathrm{LP}\left(\mathrm{C}_{1}-\mathrm{O}\right)$ & $\mathrm{BD}^{*} \mathrm{C}_{1}-\mathrm{C}_{2}$ & 21.88 \\
& $\mathrm{LP}\left(\mathrm{C}_{1}-\mathrm{O}\right)$ & $\mathrm{BD}^{*} \mathrm{C}_{1}-\mathrm{H}$ & 21.39 \\
\hline $\mathrm{c}$ & $\mathrm{LP}\left(\mathrm{C}_{2}-\mathrm{O}\right)$ & $\mathrm{BD}^{*} \mathrm{C}_{5}-\mathrm{O}$ & 12.95 \\
\hline \multirow{2}{*}{$\mathrm{d}$} & $\mathrm{LP}\left(\mathrm{C}_{3}-\mathrm{O}\right)$ & $\mathrm{BD}^{*}\left(\mathrm{C}_{2}-\mathrm{O}\right)-\mathrm{H}$ & 1.16 \\
& $\mathrm{LP}\left(\mathrm{C}_{1}-\mathrm{O}\right)$ & $\mathrm{BD}^{*} \mathrm{C}_{5}-\mathrm{O}$ & 12.69 \\
\hline \multirow{2}{*}{$\mathrm{e}$} & $\mathrm{LP}\left(\mathrm{C}_{2}-\mathrm{O}\right)$ & $\mathrm{BD}^{*} \mathrm{C}_{1}-\mathrm{C}_{2}$ & 12.28 \\
& $\mathrm{LP}\left(\mathrm{C}_{2}-\mathrm{O}\right)$ & $\mathrm{BD}^{*} \mathrm{C}_{2}-\mathrm{C}_{3}$ & 11.26 \\
& $\mathrm{BD}\left(\mathrm{C}_{1}-\mathrm{H}\right)$ & $\mathrm{BD}^{*}\left(\mathrm{C}_{3}-\mathrm{O}\right)-\mathrm{H}$ & 10.22 \\
\hline
\end{tabular}


TABLE-4

ELECTRONIC ENERGY, ZERO POINT ENERGY AND THE RELATIVE ENERGY

\begin{tabular}{ccccc}
\hline Molecule & $\mathrm{E}_{\text {O(a.u.) }}$ & $\mathrm{E}_{\text {ZPE(a.u.) }}$ & $\mathrm{E}_{\text {tota.u. }}$ & $\Delta \mathrm{E}_{(\mathrm{k} / / \mathrm{mol})}$ \\
\hline $\mathrm{b}$ & -687.1257 & 0.1952 & -686.9305 & 50.6721 \\
$\mathrm{c}$ & -687.1446 & 0.1971 & -686.9475 & 6.0387 \\
$\mathrm{~d}$ & -687.1478 & 0.1980 & -686.9498 & 0 \\
$\mathrm{e}$ & -687.1279 & 0.1946 & -686.9333 & 43.3208 \\
\hline
\end{tabular}

LUMO is the lowest unoccupied molecular orbital, The HOMO-LUMO gap is used as a direct indicator of kinetic stability. A large HOMO-LUMO gap implied high kinetic stability and low chemical reactivity because it is energetically unfavorable to add electrons to a high-lying $\mathrm{LUMO}^{33}$ or to extract electrons from a low-lying $\mathrm{HOMO}^{34}$. Also $\Delta \mathrm{E}$ is the value of HOMO-LUMO gap and $\Delta \mathrm{E}$ is more lesser the electron transition is more easy, the molecule is more unstable.

It is shown that inulin molecule is more unstable than the others because the $\Delta \mathrm{E}=3.75 \mathrm{eV}$ is the lowest in Fig. 4 and electron could transit from the primary alcohols at end of the molecule to the carbonyl bond $(\mathrm{C}=\mathrm{O})$, the right atom of the primary alcohol is the best active site which could lose electrons. The activity of glucose molecule mainly controlled aldehyde group which has large contribution to the HOMO orbit and LUMO orbit. It is shown that the electronic transition of pyran-fructose is very difficult because $\Delta \mathrm{E}=7.51 \mathrm{eV}$ is the maximum energy gap than the others and the track comparison of LUMO orbit is disperses, covering the total pyran ring, all that have shown the molecule has a better acceptance electronic property. Furan fructose's frontier orbit is shown as d in Fig. 4, the HOMO orbital distribution is relatively dispersed and $\Delta \mathrm{E}$ $=6.81 \mathrm{eV}$ is relatively large, so the electronic transition is not easy, the LUMO orbital is contributed from oxygen atom orbit which is connected with $\mathrm{C}_{4}$ atom. While there is linear structure in $\mathrm{b}$ and e molecule, but there is one aldehyde radical in $\mathrm{b}$ molecule and not same as in e molecule, so there is different energy in $\mathrm{b}$ and e molecule. Contrast the value of $\Delta \mathrm{E}$, we have derived the stability of molecules is: e $<\mathrm{b}<\mathrm{d}<\mathrm{c}$, pyranfructose molecule is the most stable.
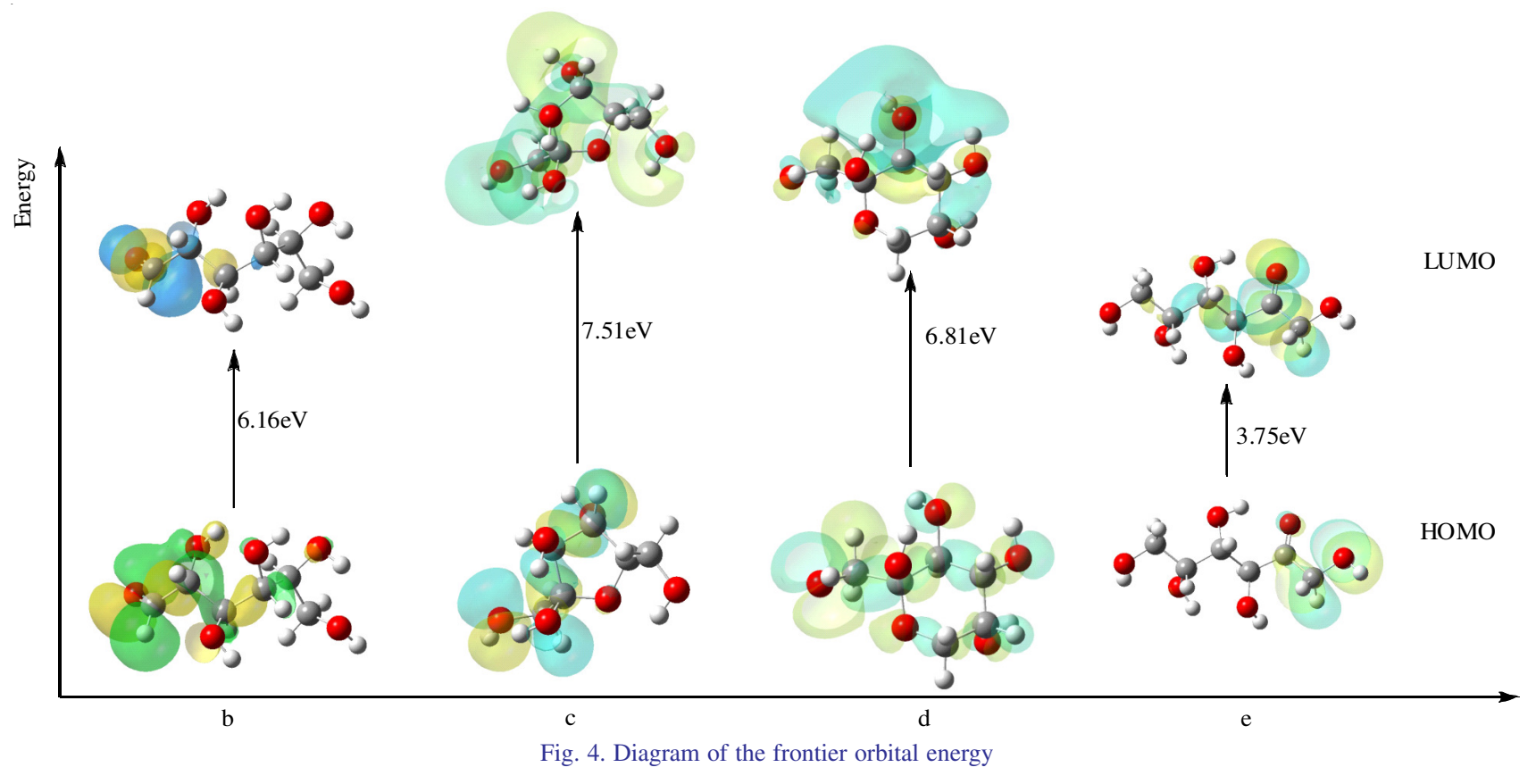

Concept DFT and Fukui index calculations: Recently, concept active index DFT $\left(\mu, \eta, \omega, \Delta \mathrm{E}_{\mathrm{n}}, \Delta \mathrm{E}_{\mathrm{e}}\right)$ have the wide application ${ }^{17,18,35}$ both in the inorganic and organic system. If material is in the transition state, the chemical potential $\mu$ would be the highest and the chemical hardness $\eta$ is the lowest, so the molecule is in an unstable state, so the opposite state is that when the material is in steady state, chemical potential $\mu$ would be the lowest and it's chemical hardness $\eta$ is the highest. The electrophilic index $\omega$ could show that the bind degree between molecule with electrophilic reagent, also the nucleophilic force differential index $\Delta \mathrm{E}_{\mathrm{n}}$ and the electrophilic force differential index $\Delta \mathrm{E}_{\mathrm{e}}$ is indicated the activity degree of nucleophilic or electrophilic. All concept active index are listed in Table-5, we have found that the volume and the specific surface area of $\mathrm{c}$ and $\mathrm{d}$ molecule have decreased because the formation of cyclic structure in molecules, but molecular volume and surface area of $b$ or e molecule still more larger because of straight chain. The order of ionization potentials is $c>b \approx d>$ e and the ionization potential of inulin molecule is lowest. Electron affinity representation of $\mathrm{c}$ or $\mathrm{d}$ molecule are negative, so their energy would decrease after accepting electron into anion, but the electron affinity represent-tation of e molecule is much larger than the b molecule, which could indicated that it's energy would increase after accepting electron into anion and the stability of anion also become lower. The chemical potential $\mu$ of e molecule is the maximum and the chemical hardness $\eta$ is the lowest, which could certify e molecule is at relatively stable state, the chemical potential $\mu$ of pyran-molecule is lesser and chemical hardness $\eta$ is maximum, which maybe because whole molecule structure is 
unstable and the tension tension of ring is so large that it could easily accommodate electron. The electrophilic index $\omega$ of e molecule is the maximum, which could have greatest activity and the electrophilic capability is better. Compared their $\Delta \mathrm{E}_{\mathrm{n}}$ and $\Delta \mathrm{E}_{\mathrm{e}}$, we have found the value of $\Delta \mathrm{E}_{\mathrm{n}}$ in e molecule is the maximum and the value of $\Delta \mathrm{E}_{\mathrm{e}}$ in e molecule is the lowest, so the inulin molecule have better nucleophilic force, so it could become a better antioxidant drug.

In order to understand the molecular activity, we have carried out the local atomic Fukui index calculation of inulin molecule and the results are listed in Table-6. On analysis of the data, we have found the $f_{(\mathrm{r})}^{-}, f^{+}{ }_{(\mathrm{r})}, f_{(\mathrm{r})}^{0}$ values of six carbon atoms in inulin molecule are different and the $f^{+}(\mathrm{r})$ value of $\mathrm{C}_{2}$ atom is the maximum, so its ability of gain electron is the strongest, while the $f_{(\mathrm{r})}^{+}$value of $\mathrm{C}_{4}, \mathrm{C}_{5}, \mathrm{C}_{6}$ atom are negative, that could indicate obtaining electronic is unable, while the $f_{(\mathrm{r})}^{-}$value of $\mathrm{C}_{2}$ atom is the maximum, that could indicate losing electron is easy, all carbon atom except $C_{3}$ atom could lose electron. In contrast to the $f_{(\mathrm{r})}^{+}$value, the electronic contribution is more distinceness, so the total molecule could be able to lose electron. Analysis of $f_{(\mathrm{r})}^{0}$ value of all carbon atom, the most active atom is $\mathrm{C}_{2}$ atom. The Fukui index of oxygen atom could indicated $f_{(\mathrm{r})}^{-}$and $f_{(\mathrm{r})}^{+}$value of the oxygen atom are maximum which has attached to the $\mathrm{C}_{6}$ atom, so it is able to easy capture electron. The $f_{(\mathrm{r})}^{+}$value of oxygen atom which has attached to the $\mathrm{C}_{2}$ atom is lowest so that it is unable for $\mathrm{C}_{2}$ atom to accept electron and only could lose electron.

Evaluation about the ability of antioxidant: In pharmacology, inulin molecule has very good antioxidant properties ${ }^{36,37}$, which could achieve the purpose through take place the reaction with the hydroxyl free $\operatorname{radical}\left({ }^{\circ} \mathrm{OH}\right)$ or the superoxide anion free $\operatorname{radical}\left(\mathrm{O}_{2}^{-\bullet}\right)$. The reaction mechanism of disposal free radical mainly been accomplished by the role of hydroxyl's dehydrogenation, which could assess by $\mathrm{E}_{\mathrm{BDE}}$ and IP value. Therefore, we have calculated the $\mathrm{E}_{\mathrm{BDE}}$ value of the different hydrogen atom on the base of the stable molecular structure which have been optimized by B3LYP method and the hydrogen atoms in inulin molecule are numbered as shown in Fig. 5, the $\mathrm{E}_{\mathrm{BDE}}$ value of the different hydrogen atom are listed in Table-7.

The data in Table-7 have shown that the $\mathrm{E}_{\mathrm{BDE}}$ value of hydrogen in different position is different, when the value of $\mathrm{E}_{\mathrm{BDE}}$ is lesser, this position is easy to provide hydrogen atom and antioxidant ability is stronger. We have found $2-\mathrm{H}$ is the most easily been broken because its $\mathrm{E}_{\mathrm{BDE}}$ value is lowest, which is due to the strongly attract electron effection of near carbonyl $(\mathrm{C}=\mathrm{O})$. But the value of $\mathrm{E}_{\mathrm{BDE}}$ is relatively high for $3-\mathrm{H}$ and it is approximately $28.58 \mathrm{~kJ} / \mathrm{mol}$ than the value of $2-\mathrm{H}$. We have calculated the vertical ionization potential of inulin molecule by the use the same method and its value is $196.56 \mathrm{kcal} \mathrm{mol}^{-1}$. We have found that the adiabatic ionization potential of inulin molecule is $183.15 \mathrm{kcal} \mathrm{mol}^{-1}$, all of that could show its ionization energy is more large, so the value of $\mathrm{E}_{\mathrm{BDE}}$ to explain the antioxidant activity is more reasonable.

\begin{tabular}{cccc}
\multicolumn{4}{c}{ TABLE-7 } \\
\multicolumn{4}{c}{$\mathrm{E}_{\mathrm{BDE}}$ ENERGY OF DIFFERENT POSITION HYDROGEN } \\
\hline & $\mathrm{SPE}_{\mathrm{f}}$ (a.u.) & $\mathrm{ZPV}_{\mathrm{p}}\left(\mathrm{kJ} \mathrm{mol}^{-1}\right)$ & $\begin{array}{c}\mathrm{O}-\mathrm{H} \\
\mathrm{E}_{\mathrm{BDE}} /\left(\mathrm{kJ} \mathrm{mol}^{-1}\right)\end{array}$ \\
\hline Molecule & -687.127937 & 511.068278 & \\
$1-\mathrm{H}$ & -686.459871 & 470.287437 & 407.471927 \\
$2-\mathrm{H}$ & -686.465734 & 474.290536 & 396.003258 \\
$3-\mathrm{H}$ & -686.454712 & 473.926642 & 424.585545 \\
$4-\mathrm{H}$ & -686.459414 & 473.009817 & 411.340801 \\
$5-\mathrm{H}$ & -686.456683 & 471.023627 & 416.563519 \\
\hline
\end{tabular}

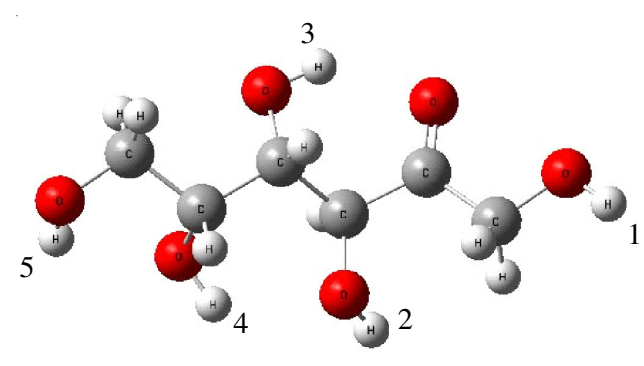

Fig. 5. Hydrogen atom's number in inulin molecule

\begin{tabular}{|c|c|c|c|c|c|c|c|c|c|}
\hline \multicolumn{10}{|c|}{$\begin{array}{c}\text { TABLE-5 } \\
\text { CONCEPT DFT INDEX OF FOUR MOLECULES }\end{array}$} \\
\hline Molecule & $\mathrm{V} \mathrm{Bohr}^{3}$ & SA Bohr ${ }^{2}$ & $\mathrm{IeV}$ & $\mathrm{AeV}$ & $\mu \mathrm{eV}$ & $\eta \mathrm{eV}$ & $\omega \mathrm{eV}$ & $\Delta E_{n} \mathrm{eV}$ & $\Delta \mathrm{E}_{\mathrm{e}} \mathrm{eV}$ \\
\hline $\mathrm{b}$ & 1358.18 & 707.21 & 6.52 & 0.36 & 3.44 & 6.16 & 0.96 & 7.48 & 0.60 \\
\hline $\mathrm{c}$ & 1287.23 & 669.13 & 6.72 & -0.77 & 3.48 & 7.49 & 0.81 & 8.03 & 1.07 \\
\hline d & 1313.91 & 666.31 & 6.50 & -0.29 & 3.11 & 6.79 & 0.71 & 7.22 & 1.00 \\
\hline $\mathrm{e}$ & 1329.88 & 708.32 & 6.45 & 2.71 & 4.58 & 3.74 & 2.80 & 9.25 & 0.09 \\
\hline
\end{tabular}

\begin{tabular}{ccccccc}
\multicolumn{7}{c}{ TABLE-6 } \\
\multicolumn{7}{c}{ FUKUI FUNCTION ANALYSIS OF KEY ATOMS IN INULIN MOLECULE } \\
\hline Atom & $\rho_{\mathrm{N}(\mathrm{r})}$ & $\rho_{\mathrm{N}-1(\mathrm{r})}$ & $\rho_{\mathrm{N}+1(\mathrm{r})}$ & $f^{?}(\mathrm{r})$ & $f^{+}(\mathrm{r})$ & $f^{0}(\mathrm{r})$ \\
\hline $\mathrm{C}_{1}$ & 0.1581 & 0.1698 & 0.1448 & 0.0117 & 0.0133 & 0.0125 \\
$\mathrm{C}_{2}$ & 0.4679 & 0.5677 & 0.1925 & 0.0998 & 0.2754 & 0.1876 \\
$\mathrm{C}_{3}$ & 0.0238 & 0.0023 & 0.0088 & -0.0215 & 0.0150 & -0.0033 \\
$\mathrm{C}_{4}$ & 0.0426 & 0.0731 & 0.0701 & 0.0305 & -0.0275 & 0.0015 \\
$\mathrm{C}_{5}$ & 0.0423 & 0.0457 & 0.0490 & 0.0034 & -0.0067 & -0.0017 \\
$\mathrm{C}_{6}$ & 0.0981 & 0.1264 & 0.1081 & 0.0283 & -0.0100 & 0.0092 \\
$\mathrm{C}_{1}-\mathrm{O}$ & 0.7223 & 0.7123 & 0.7316 & -0.0100 & -0.0093 & -0.0097 \\
$\mathrm{C}_{2}-\mathrm{O}$ & 0.4818 & 0.3757 & 0.7650 & -0.1061 & -0.2832 & -0.1947 \\
$\mathrm{C}_{3}-\mathrm{O}$ & 0.7246 & 0.7175 & 0.7908 & -0.0071 & -0.0662 & -0.0367 \\
$\mathrm{C}_{4}-\mathrm{O}$ & 0.7440 & 0.6914 & 0.8052 & -0.0526 & -0.0612 & -0.0569 \\
$\mathrm{C}_{5}-\mathrm{O}$ & 0.7688 & 0.7348 & 0.7926 & -0.0340 & -0.0238 & -0.0289 \\
$\mathrm{C}_{6}-\mathrm{O}$ & 0.7637 & 0.5236 & 0.7756 & -0.2401 & -0.0119 & -0.1260 \\
\hline
\end{tabular}




\section{Conclusion}

We have found the stability order is furan-fructose $>$ pyranfructose $>$ glucose $>$ inulin, through the geometric structure optimization, frequency analysis, infrared spectroscopy, the atom charge population, NBO analysis and the frontier orbital energy calculation by DFT method. On this basis, we have used the concept of DFT activity index to analyze the inulin molecule, the numerical chemical potential of inulin molecule is large, the chemical hardness of inulin molecule is small and the electrophilic index is large, which have been shown that it has a special activity. The $\mathrm{C}_{2}$ atom is the active center of the whole molecule because its lager ability of losing one electron through the Fukui index scanning. Calculations of $\mathrm{E}_{\mathrm{BDE}}$ have showed that $2-\mathrm{H}$ is the most easily broken, that is far less than the adiabatic ionization potential, all these is a reasonable theoretical interpretation for the pharmacological activity of inulin.

\section{ACKNOWLEDGEMENTS}

The author are grateful to the Hengyang City Natural Science Foundation of China (No.2013kj23) for its financial support for this project.

\section{REFERENCES}

1. H.Y. Zhang, L.F. Wang and Y.M. Sun, Bioorg. Med. Chem. Lett., 13, 909 (2003).

2. J.H. Roe, J.H. Epstein and N.P. Goldstein, J. Biol. Chem., 178, 839 (1949).

3. Y. Zhang, T.H. Chen and J.T. Sun, Chem. Bull., 65, 12 (1998).

4. G.R. Gibson, E.R. Beatty, X. Wang and J.H. Cummings, Gastroenterology, 108, 975 (1995).

5. R.A.A. Muzzarelli, J. Boudrant, D. Meyer, N. Manno, M. DeMarchis and M.G. Paoletti, Carbohydr. Polym., 87, 995 (2012).

6. S. Stoyanova, J. Geuns, E. Hideg and W. Van Den Ende, Int. J. Food Sci. Nutr., 62, 207 (2011).

7. P. Andrewes, J.L.H.C. Busch, T. de Joode, A. Groenewegen and H. Alexandre, J. Agric. Food Chem., 51, 1415 (2003).

8. K. Seki, K. Haraguchi, M. Kishimoto, S. Kobayashi and K. Kainuma, Agric. Biol. Chem., 53, 2089 (1989).

9. Y.J. Zhang, Anal. Chem., 5, 167 (1977).

10. Y.M. Sun, H.Y. Zhang, D.Z. Chen and C.-B. Liu, Org. Lett., 4, 2909 (2002).
11. J. Luo, S.W. Rizkalla and C. Alamowitch, Am. J. Clin. Nutr., 96, 939 (1996).

12. J.M. Laparra, E. Tako, R.P. Glahn and D.D. Miller, Food Chem., 109, 122 (2008).

13. Z.M. Chi, T. Zhang, T.S. Cao, X.-Y. Liu, W. Cui and C.-H. Zhao, Bioresour. Technol., 102, 4295 (2011).

14. K.G. Jackson, G.R. Taylor, A.M. Clohessy and C.M. Williams, Br. J. Nutr., 82, 23 (1999).

15. L.J. Pauling, J. Am. Chem. Soc., 62, 2643 (1940).

16. M. Azenha, P. Kathirvel, P. Nogueira and A. Fernando-Silva, Biosens. Bioelectron., 23, 1843 (2008).

17. A.D. Becke, J. Chem. Phys., 97, 9173 (1992).

18. R.G. Parr and W. Yang, J. Am. Chem. Soc., 106, 4049 (1984).

19. K. Fukui, J. Phys. Chem., 74, 4161 (1970).

20. M.P. Andersson and P. Uvdal, J. Phys. Chem. A, 109, 2937 (2005).

21. A.P. Scott and L. Radom, J. Phys. Chem., 100, 16502 (1996).

22. M. Szafran, A. Komasa and E. Bartoszak-Adamska, J. Mol. Struct., 827, 101 (2007).

23. B. Miehlich, A. Savin, H. Stoll and H. Preuss, Chem. Phys. Lett., 157, 200 (1989).

24. Y. Li and J.N.S. Evans, J. Am. Chem. Soc., 117, 7756 (1995).

25. R.G. Pearson, Chemical Hardness, Structure and Bonding, SpringerVerlag: Berlin (1993).

26. S.B. Liu, Acta Phys. Chim. Sin., 25, 590 (2009).

27. T. Head-Gordon, M. Head-Gordon, M.J. Frisch, C.L. Brooks and J.A. Pople, J. Am. Chem. Soc., 113, 5989 (1991).

28. R.B. Ammar, W. Bhouri, M.B. Sghaier, J. Boubaker, I. Skandrani, A. Neffati, I. Bouhlel, S. Kilani, A.-M. Mariotte, L. Chekir-Ghedira, M.G. Dijoux-Franca and K. Ghedira, Food Chem., 116, 258 (2009).

29. M.J. Frisch, G.W. Trucks and H.B. Schlegel, Gaussian03, Revision D.02; Gaussian, Inc.: Pittsburgh, PA (2003).

30. T. Lu and F.W. Chen, J. Comput. Chem., 33, 580 (2012).

31. L. Santiago-Rodríguez, M.M. Lafontaine, C. Castro, J. Méndez-Vega, M. Latorre-Esteves, E.J. Juan, E. Mora, M. Torres-Lugo and C. Rinaldi, J. Mater. Chem. B., 1, 2807 (2013).

32. K.D.O. Vigier, A. Benguerba, A. Barrault and F. Jérôme, J. Green Chem., 14, 285 (2012).

33. F. Russo, C. Clemente, M. Linsalata, M. Chiloiro, A. Orlando, E. Marconi, G. Chimienti and G. Riezzo, Eur. J. Nutr., 50, 271 (2011).

34. Y. Ruiz-Morales, J. Phys. Chem. A, 106, 11283 (2002).

35. P. Geerlings, F. Deproft and W. Langenaeker, Chem. Rev., 103, 1793 (2003).

36. E.M. Dewulf, P.D. Cani, A.M. Neyrinck, S. Possemiers, A.V. Holle, G.G. Muccioli, L. Deldicque, L.B. Bindels, B.D. Pachikian, F.M. Sohet, E. Mignolet, M. Francaux, Y. Larondelle and N.M. Delzenne, J. Nutr. Biochem., 22, 712 (2011).

37. B.S. Reddy, R. Hamid and C.V. Rao, Carcinogenesis, 18, 1371 (1997). 